\title{
The Dependence Dilemma and Dominant Equilibrium of the Environmental Governance's Regulatory Path
}

\author{
Qinglong Wang \\ School of Economics \\ Sichuan University \\ Chengdu, China
}

\author{
Weina Qin \\ School of International Relations \\ Sichuan University \\ Chengdu, China
}

\begin{abstract}
As a common resource, public resources are nonexclusive and competitive, and too much of them will lead to external problems. Western property rights theory thinking that property right is a social force, a variety of uses and implementation of some economic goods the right to choose, if the property can be clearly defined, the use of public resources when externalities caused environmental pollution problems can be resolved through internal, vendors and the public through bargaining between the two sides finally negotiated consensus of public resource use. For no clear property rights, which caused the environmental problems, it need to government intervention, the government through the control of pollution sources of vendors, warning, selective examination, subsidies and tax measures allow manufacturers to reduce pollution emissions. In this paper, from the perspective of property rights are clearly defined and game theory method to study the governance process of the environmental pollution, it is concluded that, if property right is clear, the environmental pollution through internal bargaining can be governance. If property rights are fuzzy, it needs the cooperation between government and enterprise, or fees and subsidy way, which is out of the dilemma choice of path depending on both sides of dominant equilibrium, so as to control the optimal amount.
\end{abstract}

Keywords-property rights; environmental pollution; game

\section{INTRODUCTION}

Along with the development of the economy, the natural environment and ecological environment is increasingly damaged, human in order to maintain the good development of economy, the consumption of natural resources and misuse of resources, not only make the resources increasingly depleted, but seriously pollute the environment. In order to ensure the sustainable and healthy development of the economy, the government has also begun to intervene in the implementation of environmental control and through various sanctions to restrict the emission of micro-economic individuals. Although many measures can achieve the effect of pollution control in theory, the microeconomic individuals who discharge pollutants in practice still ignore the government's policies from the perspective of maximizing their own interests. The externalities of environmental pollution are flow externalities and stock externalities, so controlling pollution through the spontaneous way of the market is a phenomenon of market failure. Excessive intervention by the government may also fail to achieve the best environmental policies, resulting in government failure. Therefore there will be a dilemma, which makes the path of environmental regulation on, the text based on the above analyses that government should break this depend on the path, to find a dominant strategy providing reference basis for environmental pollution control.

\section{LITERATURE REVIEW}

The implementation of environmental pollution control is the inevitable policy conclusion of old welfare economics based on its analysis of "externality" and "market failure" in the market economy. According to the old welfare economics, environmental pollution is a typical phenomenon of "market failure", which cannot be solved by market means alone. Therefore, the government must intervene. This is also one of the earliest reasons why western governments intervene in economic activities. When Property rights clearly defined, the Coase (1960 Ronald Coase, The problem of social cost), from the perspective of the external impingement, discussed negative externality, namely the foreign invasion and certain economic mainly body behavior causes damage to the external problem. On this basis, the famous the Coase theorem is proposed, which seeks solutions through the selection of transaction costs and private negotiations depending on the proper definition and implementation of property rights. If negotiations or trading is no cost, the social cost produced by the external trade will be included in the cost function of the parties, the government need to properly define property rights, withou the interference of production, the private trading can overcome externalities caused efficiency loss; If have cost, in a clearly defined property rights, market transactions, internal integration, government management of a variety of different rights arrangement, the parties use to a contract for a low cost system arrangement and increase production value which is greater than the operating costs, so as to achieve the Pareto optimal state.

Property right is not very good when clearly defined, Pigou (Pigou, A.C., 1920, The Economics of Welfare, Macmillan, London. The Fourth edition, 1932) starting from the problem of "public products", analyze the differences of marginal social pure product and marginal private net product to explain the causes of externalities. It is believed that the external effect is caused by the deviation between 
marginal private cost and marginal social cost, marginal private benefit and marginal social benefit. When there are externalities, the market price does not reflect the marginal social cost of production, namely the private cost can't measure economic effect, the market mechanism will not run on its own at the pareto optimality status of resource allocation. To solve market failure, government should take appropriate economic intervention policy to eliminate the divergence, Pigou suggested that the marginal private cost less than the tax department of marginal social cost, the tax is equal to the difference between them. Through the tax to change enterprise production technology and processes or preventive measures to reduce emissions of pollutants, which encourage enterprises to develop new environmental technology, so as to make the environmental externalities internalized by levy "Pigou tax".

\section{THE PROPERTY RIGHTS COMMUNITY HAS DECIDED TO SOLVE THE DILEMMA OF ENVIRONMENTAL POLLUTION DEPENDENCE}

Property rights are legal rules that describe what people or companies can do with their property. We assume that the manufacturer has the right to use the air, and the public air around the manufacturer has no property right, so the manufacturer will not include the cost of emissions into the cost of production. In other words, manufacturers have externalized the cost of emissions. Assuming that the public around the manufacturer owns the right to clean air, the public has the right to demand payment from the manufacturer when the manufacturer releases the exhaust gas. When the cost of exhaust gas is internalized, the efficient allocation of air resources will be realized. Economic efficiency can be achieved without government intervention when there are relatively few aspects of external impacts and property rights are well defined.

\section{A. Model Setting}

TABLE I. EFFECTIVENESS OF DIFFERENT POLLUTANT DisCHARGE OPTIONS EACH YeAR

\begin{tabular}{|l|l|l|l|l|}
\hline \multicolumn{2}{|l|}{ The utility of the factory } & publicutility & Total utility \\
\hline Unfiltered equipement & Airless purification & 3 & 1 & 4 \\
\hline With filtering equipment & Airless purification & 1 & 4 & \\
\hline Unfiltered equipment & With air purification & 3 & 2 & 5 \\
\hline With filtering equipment & With air purification & 1 & 5 & 5 \\
\hline
\end{tabular}

Assuming that the manufacturer's emissions reduce the utility of public access to clean air, the manufacturer's free emission of pollution will increase the utility, measured these utility by currency. As shown in "Table 1", in the process of bargaining, vendors can install a filtering system to reduce emissions, or manufacturers around the public through in the home install air purifier and go out wearing respirators to reduce the harm of pollution. Assuming that the factory has a property right to air at the beginning, it has the right to emit gases at will. After the beginning manufacturer's sewage, vendor can obtain 30000 yuan/year converted by the use of clean air production profits, at this time to bring the utility of 3 , said the public value of air brought them to the use of the 10000 yuan/year, at this time for the public utility 1 said. Assuming that it takes the manufacturer 20,000 yuan/year to install the pollutant discharge equipment, the profit of the manufacturer will be reduced. At this time, the utility of the manufacturer will be 1 , and the effect of public access to clean air will be 4 . When installing both a blowdown device and an air purifier at home, wearing a respirator outside the home is a public utility of 6 . At this time, dual pollution filtration makes clean air more valuable.

\section{B. Bargaining Between the Manufacturer and the Public}

TABLE II. BARGAINING UNDER DIFFERENT PROPERTY RIGHTS

\begin{tabular}{|l|l|l|}
\hline & Emission rights & Clean air rights \\
\hline uncooperative & & \\
\hline Utility of manufacturer & 3 & 1 \\
\hline publicutility & 2 & 4 \\
\hline cooperative & & \\
\hline Utility of manufacturer & 3.5 & 1 \\
\hline publicutility & 2.5 & 4 \\
\hline
\end{tabular}

Assuming that factory have to the property of the air emissions, the public around manufacturers for clean air install air purifier in the home, go out with the respirator, they can obtain the utility of 2 . The public is also willing to pay the same cost to give the manufacturer money, letting them to install the pollutant discharge equipment, so the utility of the manufacturer remains the same, and the utility of the public increases. Because he installed air purifiers in his home and wore a respirator when he went out, he spent 10,000 yuan per year and gained 20,000 yuan per year in the value of clean air, which increased his utility by one. Governance cost and the same to the factory can get the value of clean air for 30000 yuan/year, therefore increased 2, utility is greater than oneself the utility of the pollution treatment. If the public can reach an agreement, and they are willing to give the manufacturer half of their own extra utility, and give the manufacturer 5,000 yuan of pollution treatment subsidy every year, their utility will increase. Rational individuals will choose to work together to get 3.5 and 2.5 respectively. These bargaining solutions, shown in 
"Table II", have yielded effective results. Assuming that the public around the manufacturer has property rights to the air, it requires the factory to install the sewerage filter equipment. It takes the manufacturer 20,000 yuan/year to install the sewerage equipment, which will reduce the profit of the manufacturer, then the manufacturer's utility is 1 , the public for clean air effect of 4 , because there is no one can bargain to make things better, the initial result is efficient, the final bargaining by manufacturers and the public can maximize their utility.

\section{Efficiency of Bargaining Between the Manufacturer and the Public}

With property rights well defined, manufacturers and the public can negotiate emissions. According to Coase's theorem, no matter how the property rights are determined in advance, when the parties negotiate for the mutual benefit of both parties, if the cost of negotiation is zero, the final result is always efficient. At this time, the government did not intervene in the way of the market to control pollution. The definition of property right makes the externality of pollutant discharge through the transaction and cooperation of both parties. The final total social utility is 6 and 5.From the point of view of the whole society, however, the result of this bargaining is the pareto improvement of social public resources. When there is no way to define property rights or when the cost of negotiation is very high, relying on market approach to solve environmental pollution will lead to market failure.

\section{THE DOMINANT BALANCE BETWEEN ENVIRONMENTAL REGULATION AND THE EVOLUTION PATH OF MANUFACTURERS UNDER THE GOVERNMENT'S LEADERSHIP}

\section{A. The Government Decided to Intervene in the Game Between Pollution Control and Non-pollution Control}

TABLE III. The GAME BetweEn The MANUfACTURER AND THE GOVERNMENT

\begin{tabular}{|ll|l|l|}
\hline \multirow{3}{*}{ Government } & \multicolumn{2}{c|}{ manufacturer } \\
\cline { 3 - 4 } & & \multicolumn{1}{c|}{$\begin{array}{c}\text { Pollution } \\
\text { discharge }\end{array}$} & No pollution \\
\cline { 3 - 4 } & intervene & $(-20,20)$ & $(-20,30)$ \\
\cline { 2 - 4 } & noninterference & $(0,50)$ & $(0,30)$ \\
\hline
\end{tabular}

Assume that manufacturers discharge time can obtain 500000 yuan of profits each year, when cannot drain, it can obtain 300000 yuan of profits each year, the time cost of government intervention as the supervision cost of 200000 yuan a year, the government not to interfere in the cost for 0 yuan per year. If the government intervenes now, the manufacturer will make a profit of 500,000 yuan for pollutant discharge and 300,000 yuan for non-pollution discharge. Then the manufacturer will choose a profit of 500,000 yuan for pollutant discharge. Now the government chooses not to interfere, so the manufacturer's profit from pollutant discharge is 500,000 yuan, and the profit from nonpollution discharge is 300,000 yuan, so the manufacturer will choose the profit of 500,000 yuan, and still choose to pollute. Whatever morality tells the manufacturers or chooses to pollute, their actions depend on the government's choice. When the manufacturer chooses to pollute, the cost of government intervention is 200,000 yuan per year for supervision, and 0 yuan per year for supervision without government intervention. In this case, the government will choose not to intervene. When the manufacturer chooses not to drain, the government intervention as the supervision cost of 200000 yuan a year, the government not to interfere in the supervisory cost of 0 yuan a year, then the government will still choose not to intervene, so if the government is a rational economic man, the government chose not to intervene, the game of both sides to form their own dominant strategy equilibrium. The dark part of the table 3 represents the manufacturers and the government's dominant strategy equilibrium, manufacturers choose drainage, the government chose not to governance, the market is still in a failed state, if the government and manufacturers don't cooperate, the pollution will get control.

TABLE IV. The Game Between the Manufacturer AND THE GOVERNMENT AFTER THE FINE

\begin{tabular}{|cc|c|c|}
\hline \multirow{4}{*}{ government } & \multicolumn{2}{c|}{ manufacturer } \\
\cline { 3 - 4 } & \multicolumn{1}{c|}{$\begin{array}{c}\text { Pollution } \\
\text { discharge }\end{array}$} & $\begin{array}{c}\text { No } \\
\text { pollution }\end{array}$ \\
\cline { 3 - 4 } & intervene & $(\mathrm{a}-20,50-\mathrm{a})$ & $(20,30)$ \\
\cline { 2 - 4 } & noninterference & $(0,50)$ & $(0,30)$ \\
\hline
\end{tabular}

\section{B. The Sequential Game of Government and Manufacturer Intervention}

As can be seen from the game results of the above two parties, manufacturers choose to pollute, the government chooses not to regulate, and finally there is still market failure. Now the government knows the game as a result, the government wants to through policies affect the decisionmaking behavior of manufacturers, at this time to allow manufacturers to choose either a tax or fined, the result finally make the manufacturer chooses not to drain. As shown in "Table IV", 


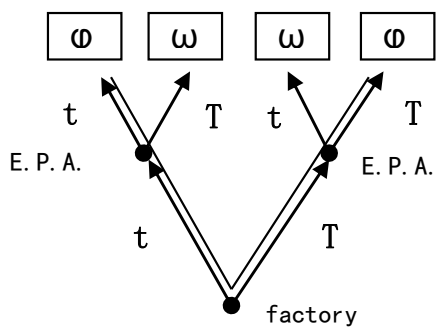

(a) Informers game

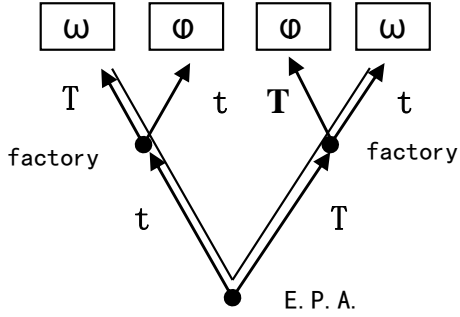

(b) Spy game

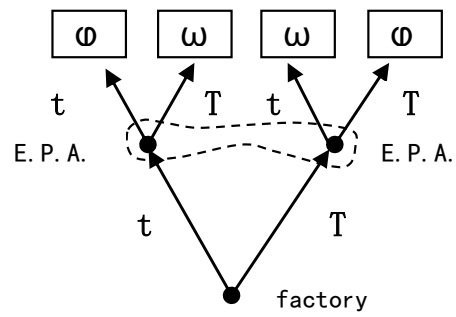

(c) Check the game

Fig. 1. Check the game.

It is assumed that the government's fine for a, as long as a fine was caught by the environmental protection agency, then give the manufacturer imposed on a fine of ten thousand yuan a year, now fine after how many vendors will consciously choose not drainage, assuming enterprise sewage caught fine and haven't caught the probability of each accounted for $50 \%$. Haven't caught the income is 500000 yuan, caught the income for ten thousand yuan (50 a), then the manufacturer's annual income expectations of 50 $* 0.5+(50-a) * 0.5$, to the manufacturer's expected income is less than the discharge of pollutants by not income 300000 yuan, namely,

$$
50 * 0.5+(50-a) * 0.5<30
$$

Solution,

$$
\mathrm{a}>40
$$

Then we get a new equilibrium, government fines, manufacturers choose not drainage, the government is not fine, manufacturers choose drainage, the decision depends on the government's action. So in this game, the government has a first-mover advantage. And the government's decision is that the manufacturer, if manufacturer choose drainage, the government chooses a fine, if the manufacturer chooses not to drainage, the government chose not to fine, and the government's decision depends on the manufacturer's decision, then the manufacturer, has a first mover advantage, so this game is a sequential game both sides take turns to act.

\section{The Government Made a Fine After the Government and the Manufacturer's Spot Check Game}

Now that the government has imposed a 450,000 yuan fine, manufacturers will still be lucky. Without penalty, the manufacturer can earn an extra 20 million yuan per year. And fine manufacturer still has 5 thousand yuan of profit (the profit that discharge pollution reduces fine $=50-45$ ), so manufacturer chooses irregular and stealthy discharge. Here's a quote from Ken Dinmore's sampling game back in the chapter, where the factory now plans to pollute today or tomorrow, and he knows that the local environmental protection agency will hear about it, but he's not worried. He was caught red-handed by inspectors before he was convicted, and the E.P.A., frustrated by its lack of manpower and impatience, may have to send inspectors out in two days. In this game, the factory has to decide whether to pollute today or tomorrow, and the E.P.A. has to decide whether to send inspectors today or tomorrow. Figure 1 shows the time structure of spot check game. The node at the bottom of the figure indicates that the factory first ACTS, and the two lines drawn by this node represent two choices of the factory: $t$ represents the factory decided to discharge the pollution today, and $\mathrm{T}$ represents the factory decided to discharge the pollution tomorrow. Each line said all point to representative nodes of environmental protection, that the next action by environmental protection bureau, so there are two in optional action: check today or tomorrow, so from the environmental protection bureau node two lines, with $\mathrm{t}$ and $\mathrm{T}$, respectively. After both the factory and the environmental protection bureau take actions, the game is over. We mark the various game results with the Chinese painting of the factory as follows: the factory has lost (the pollution has been caught) or won (the pollution has not been caught).Here are two game - Informers game and spy game, informers game is that E.P.A have an open reporting system, as long as someone reported factory drainage, and get reward after a certain reward. And the spy game is that the manufacturer buys the staff of the environmental protection bureau, and the factory knows when the environmental protection bureau will spot check it, so they choose not to spot check when they pollute. Both the result of the game is a realization of know each other's actions, that is to say they already know the information set, and finally in the informers game down the 
double line in "Fig. 1" (a) get the game results, no matter when companies choose drainage, the end result is being caught, the two lines mark the E.P.A.'s winning action. In the spy game down the double line in the "Fig. 1" (b) get the game results, no matter when companies choose spot check, the end result is can't catch, double line indicates the E.P.A. cannot win action or factory to win. By knowing that the important information in the game is the optional process of the game process, it becomes a necessary process. However, in selecting examination game because people can't know each other's information set in advance, so the result of selection is uncertainty, as shown in figure 1 (c) identified in the dotted line when plant selection of sewage pollution environmental protection bureau is impossible to know today or tomorrow, so he cannot according to the information to make a decision. From figure 2 (a) and (b) the difference is only a set of information, which is behind the two completely different game, a game is encrypted and mole, and another is not, this leads to the different information sets, different sets of information and, in turn, affect the game strategy, we will see, in the same game in the two games have different optional strategy. First of all, in the game of spot check, the factory either chooses $t$ to pollute today or $\mathrm{t}$ to pollute tomorrow. E.P.A. has only two strategies, $t$ and $\mathrm{T}$, so the payoff table for the game is very simple, as shown in figure 2 (b).In the whistle-blower game, the factory either chooses $t$ to pollute today or $\mathrm{T}$ to pollute tomorrow, but the E.P.A.'s action choice depends on the content of the secret protection, so it is necessary to distinguish its four strategies: $\mathrm{tt}, \mathrm{tT}, \mathrm{Tt}$ and TT. The first of each pair of letters indicates what the E.P.A. is going to do when the secret protection is $t$; The second letter said encrypted for T ,E.P.A. intends to take action, and the mole game just and informers game similar to the environmental protection bureau, either $\mathrm{t}$ spot check today, either $\mathrm{T}$ selective examination tomorrow, but the factory action choice depends on the encrypted content, so it is necessary to distinguish the four strategies: $\mathrm{tt}, \mathrm{tT}$, $\mathrm{Tt}$ and TT. When the first letter of each pair of letters represents the information disclosed by the traitor, the action that the factory intends to take at time $\mathrm{t}$; the second letter denotes the actions the factory intends to take when the information is disclosed by the traitor. The table of profit of the game of informer and sodomy is shown in "Fig. 2" (a). As we've already seen, the solution to the whistleblower game and the solution to the sodomy game. The factory can choose any strategy, either $\mathrm{t}$ or $\mathrm{T}$, because the environmental protection bureau wins the whistleblowing game. The environmental protection agency chooses any strategy, either $\mathrm{t}$ or $\mathrm{T}$, because the factory wins in the dirty game, but there is no definite Nash equilibrium in the spot check game.

\begin{tabular}{c|l|l|l|l|}
\multicolumn{1}{c}{ tt } & \multicolumn{1}{c}{$\mathrm{tT}$} & \multicolumn{1}{c}{$\mathrm{Tt}$} & \multicolumn{1}{c}{$\mathrm{TT}$} \\
\cline { 2 - 5 } $\mathrm{t}$ & $\varphi$ & $\varphi$ & $\omega$ & $\omega$ \\
\cline { 2 - 5 } $\mathrm{T}$ & $\omega$ & $\varphi$ & $\omega$ & $\varphi$ \\
\cline { 2 - 5 } & &
\end{tabular}

(a) informer

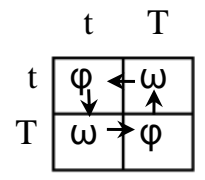

(b) without informer
Fig. 2. Profit table of the game of informer and sodomy and spot check.
TABLE V. After the Fine THE COOPERATION GAme Between the MANUFACTURER AND THE GOVERNMENT

\begin{tabular}{|c|c|c|c|}
\hline \multirow{4}{*}{ government } & & \multicolumn{2}{|c|}{ manufacturer } \\
\hline & & $\begin{array}{c}\text { Pollution } \\
\text { discharge }\end{array}$ & $\begin{array}{c}\text { No } \\
\text { pollution }\end{array}$ \\
\hline & intervene & $(10,50)$ & $(-10,40)$ \\
\hline & noninterference & $(0,50)$ & $(0,30)$ \\
\hline
\end{tabular}

\section{The Cooperation Game Between the Government and the Manufacturer After the Government Sets up the Fine and Gives the Subsidy}

It can be seen from the above game results that there is still an incentive to discharge pollution in the game of sodomy and spot check under penalty system. Now the government wants to negotiate with vendors, manufacturers must give subsidies, gives the government's supervision and cost to the manufacturer as a subsidy that the manufacturer's profit is greater than the penalty. As the discharge of pollutants has not profits, the discharge of pollutants by the vendor will automatically choose not to drain. As shown in table 5, then the manufacturer can also choose to leave part of the remaining manufacturers 100000 yuan of subsidies for their own. Therefore, the cooperation between the manufacturer and the government reduces the government's cost of governance. Meanwhile, the actions taken by the manufacturer are the dominant strategy based on the decisions made by the government.

\section{CONCLUSIONS AND CORRESPONDING SUGGESTIONS}

\section{A. Conclusion}

Under the Coase theory of property rights, if property rights can be clearly defined, the environmental pollution problem can be solved through bargaining between both parties. If the manufacturer has clean property rights, the public will be willing to subsidize the manufacturer to install sewage equipment, or buy their own anti-pollution equipment. If the public has clean property rights, the manufacturer will be willing to subsidize the public or install its own sewage equipment. When the ownership of the property as the means of production, all for the whole society, so property rights is not able to clear definition, through the market to control pollution, if depending on this path, it will lead to market failure in the end, so there is no way to be effective control of pollution. Through the adoption of Pigou method, the government through the way of cooperation and non-cooperation take a series of fine, taxes, subsidies and other way will pollute externalized internalization to solve environmental pollution problems possessed her find equilibrium, which makes effective solution to environmental pollution.

\section{B. Corresponding Suggestions}

There are two ways of thinking about pollution control. The ownership of property rights can be stipulated in the form of law in advance, so that manufacturers and the public can solve the problem of the using resources internally. When it is not possible to solve environmental problems in the property right sector, it is necessary to step out of the 
way of solving environmental problems by means of market, so as to prevent excessive emissions of pollution caused by dependence. It also can use Pigou method, by adopting intervention, cooperation, selective examination, tax and subsidy way, gradually find possession of equilibrium, the pollution of externalizing problems, which is by means of the internalization of environmental pollution problems. The final path of environmental pollution control should be dynamically adjusted to avoid the dilemma of prisoner dependence, so as to maximize social welfare.

\section{REFERENCES}

[1] Robert s. pindijk/Daniel 1. rubbienfeld. Microeconomics (6th edition) (M) renmin university of China press

[2] Pigou/dysprosium Kim/welfare economics, China xia press (M) 2007

[3] Liao Fulin. Ecological civilization and economic research (M). China forestry press. Volume 18

[4] Lin gang, zhang yu. Two paradigms of property right analysis [J]. Chinese social science,2000(1).

[5] Sheng Hong, Chen Yu. New institutional economic theory of Coase [J]. World economic research,1990(2) 